\title{
Information Integration and Information
} Strategies for Adaptive Enterprises

\author{
THEODOROS EVGENIOU, INSEAD, France
}

Enterprise information systems, such as Enterprise Resource Planning (ERP), have often been criticized for their rigidity. Alternatively, global, matrixed enterprises often follow a federated information systems approach. The first type of enterprises, which we call the standardized enterprises, lack flexibility, while the second type, which we call decentralized enterprises, lack visibility. To create what we shall call an adaptive enterprise the information systems strategy should achieve both these goals: visibility and flexibility. I discuss the problems associated with the lack of either of these two, and how information integration technology, within the enterprise application integration space, can lead to the creation of adaptive enterprises. (C) 2002 Elsevier Science Ltd. All rights reserved.

Keywords: Data warehousing, Information integration, IT strategy, Enterprise application integration (EAI)

\section{Introduction}

Despite continued investments in large enterprise information systems, scenarios of the following type appear almost every day: that in spite of many new accounts sales are not up, executives want to learn quickly where they are bleeding and fix it, but the standard reports they receive by querying the information systems do not give them any insights into how to achieve this. The problem typically is that the required information is spread across different nonintegrated systems, customers and products have been defined and grouped in all sorts of ways across different business units and regions, and information and process inconsistencies are lurking everywhere across the enterprise. There is still no way to have demands of this type answered quickly and, even more important, accurately and consistently. Then there is the other scenario: disappointed with such delays, inconsistencies, and lack of visibility across the enterprise, executives decide that all information - and associated processes - are standardized across the organization, everything is stored in the same central information repository. For example, all salespeople should be required to use a unique information system, and they must also all 'define' customers the same way and describe products and offerings in pre-agreed ways. It may seem that such an approach would fix the initial problems, but the truth is that instead it creates many more headaches for the employees and the organization. For example, what if the salespeople of a unit need to also keep track of information about their customers that is unique to the region where they operate? Why should ' $G E^{\prime}$ mean the same to both the machinery purchasing department and the financial unit? Even worse, what if the organization merges with another company or buys a new one? Would new employees also follow the designed information and process recipes? The answer is clear. Putting an enterprise into an enterprise system - instead of the other way around (Davenport, 1998) - is clearly also problematic, constraining and thus lowering the performance of individual units and therefore of the organization as a whole.

Organizations are stuck between these two worlds: either suffering from lack of information visibility across the enterprise, or aimlessly forcing common practices in order to increase visibility but then quickly finding themselves suffering from information inflexibility. Getting the best of both worlds is becoming a new requirement, rarely achieved with 
existing information systems such as ERP and corporate data warehouses. Key to the creation of a fully information aware and highly flexible organization is the creation of the adaptive enterprise. This is the kind of enterprise that can quickly adapt to change, make better informed real-time decisions, and have clear visibility of both its internal and external environment.

Market forces require constant strategy re-alignment, restructuring, acquisitions and divestment. New regulations require new, robust reporting techniques, and rapid market downturns demand consolidation of business and product portfolios. Management has no time to lose if it wants to capitalize on a new opportunity or survive a market maelstrom. They want a global view but one compiled from quality information throughout the value chain and from the very bottom of the organization. In today's global competitive environment, executives need fast access to timely accurate information on any aspect of the business, at any level, from any perspective, no matter how much or how often it changes, and the ability to keep this high visibility across the entire organization through major changes in the internal and external environment. What we define to be an adaptive enterprise is an ideal but attainable state in which boards can gain the information they need at the speed at which the market moves, through any internal or external changes.

In this paper I first discuss the key reasons why enterprises today have typically either lost their flexibility or their visibility, two notions defined below, because of their IT strategy, therefore becoming either standardized or decentralized enterprises. I then discuss the key decisions that boards have to make today that require an IT strategy that must lead to organizations with both high visibility and high flexibility. Satisfying this requirement leads to the creation of an adaptive enterprise, discussed next. Finally there is a discussion of how managers can develop an IT strategy in order to build such an enterprise based on the promises of information integration technology within the Enterprise Application Integration (EAI) market.

\section{Which IT Strategies Stop an Enterprise From Being Adaptive?}

Few global companies can currently claim to have achieved true visibility and flexibility in corporate information systems. Visibility is the ability to have multiple views of the business at a global level: the board can explore performance information extracted from disparate systems and view it from any perspective and at any level of detail i.e. global, regional, local, product, and customer. Flexibility is the ability to remain flexible globally and locally as the organiza- tion changes. It is flexibility in terms of IT policy across the organization: different units typically have different information processes and needs. Companies typically lack one or the other, or both.

Firstly, there has been an accumulation of disparate information systems over the years, exacerbated by ceaseless mergers and acquisitions and the wholesale uptake of enterprise information systems. The race to become technologically advanced; e-business initiatives; enterprise resource planning (ERP); customer relationship management (CRM); supplier relationship management (SCM); and knowledge management, are just some of the trends that have led to federated, disconnected information systems. The Meta Group estimates that the average corporation has more than 49 different databases operating simultaneously, while at the same time IDC estimates that as much as 70 per cent of the average IT department's budget is devoted to data integration projects. Not only is different information represented by different data in different sections across different business units and functions, but it is also duplicated in many areas, and errors are lurking everywhere. This lack of visibility has a negative effect on key business metrics such as sales, customer satisfaction and profitability.

Secondly, the degree of flexibility within local operating units can have a significant effect on the quality of information received by management. Whether or not the organization adheres to a decentralized or centralized strategy, flexibility is an issue. If a decentralized approach is chosen, then local business units will only gather the data they find useful in the formats they choose. They will come to rely on regional or global resources to take on the burden of data harmonization. If the cost is pushed back to them, lengthy, time-wasting arguments and debates on cost allocation will often ensue. Moreover, any requests for change will invariably be reluctantly and sluggishly responded to or, at worst, rejected. The business will remain highly flexible at a local level but visibility of information at a global or regional level will be poor.

If the centralized model is chosen then all business units have to work the same way. This can improve visibility of data at a global level but can reduce flexibility. Dell Computers spent two years and $\$ 200 \mathrm{~m}$ trying to standardize one enterprise software package to add to its fulfilment systems and gave up as it found the software too 'monolithic'. Instead it opted for a 'best-of-breed' software strategy - more expensive to integrate but easier to work with once installed. Davenport comments on the example of an industrial products manufacturer that has built its strategy around extraordinary customer service and its ability to deliver parts to customers 25 per cent faster than competitors. With the installation of an ERP system and a more rational, less flexible process for filling orders it had better quality data but slower response times. It lost its competitive edge. 
Thirdly, the impact of change can hamper an organization's ability to view key business metrics at a global level whatever the chosen IT strategy. The relationship between each piece of data breaks down once an assumption that links them together e.g. business unit and product, is invalidated. For this reason many multi-nationals have tried, mainly unsuccessfully, to build their own proprietary data warehouses using their own business rules. Unfortunately the prediction of change is extremely complex and few are able to deliver return-on-investment within the allocated budgets and timescales.

On top of all this, the advent of the extended enterprise has made access to quality, up-to-date information even more challenging. Data now resides not just across multiple business units but also across customers, partners and suppliers. The challenge is to harness and formulate all this information fast and flexibly enough for the top management to make the right decisions before the competition. Otherwise the quality of top management's decisions is at risk, as discussed in the next section.

\section{The Requirements of Board Decision- makers}

For any global decision-maker there are three generic aspects of the business where they need visibility of critical information and the flexibility to keep track of this critical information throughout major changes organization, product and customer. Here are just a few examples of the challenges facing boards in each case.

\section{Organization}

Global organizational structures are highly complex, with matrix management the norm rather than the exception. Global businesses such as those in the telecommunications sector are managed by company, product group and customer account simultaneously. Management need to be able to view business performance from any of these perspectives. If they restructure the business so that, for example, P\& L's are driven by global product groups rather than country business units, they need to be able to assess business performance by product group with subsets such as sales team, customer, channel and country.

Moreover, organizations need to be able to integrate and manage acquisitions fast. Well-integrated acquisitions can drive above-average business growth. Recent studies by McKinsey of companies in the hitech sector since 1989 show that the top performing companies undertake twice as many acquisitions as their competitors. However, effective post-acqui- sition integration is very hard to execute. A study by Southern Methodist University in the US of 193 mergers over $\$ 100 \mathrm{~m}$ between 1990 and 1997 found that only 36 per cent maintained revenue growth in the following quarter.

Data integration facilitates the collection, comparison, and aggregation of data from various parts of the organization, including newly acquired ones, also leading to a better understanding when there are complex, interdependent problems. For example, when on-time deliveries of an electronics corporation fell to only 70 per cent, organization-wide integrated data enabled the company to understand its problems that were dispersed across local plants which did not update inventory levels correctly to marketing units overriding schedules, thus improving its on-time deliveries to 98 per cent (Goodhue et al., 1992a). Generally, more effective supply chains can be achieved with better visibility across the chain. With integrated information from all stages in the supply chain, organizations can better optimize: from answering every day questions like how many parts to order, when parts arrive, and what is the average unit cost of a particular from all suppliers, to achieving just-in-time, optimizing inventory levels, and strategically choosing which suppliers to keep, upgrade, or cease working with.

Global decision-makers need to have fast and regular access to information such as:

* How could I restructure my business to achieve a stock-re-rating?

* What impact has a raw material price rise had on each country business unit and what impact will a further rise have?

* What are the revenues and profits of a newly merged business?

* What would the impact on revenues be if we bought out our joint-venture partners?

* Who are our top global suppliers and with whom could we obtain greater purchasing power?

\section{Product}

Many global corporations are undertaking radical surgery with their brand portfolios today. Many successful consumer brands are global brands with a core brand essence and promise, but tailored to local markets. Such brands require huge resources to maintain and grow so the selection of and focus on potential winners is a high-risk business.

Global organizations struggle to gain quality and upto-date information on their brand portfolio performance. Disparities in packaging, ingredients, pricing, channel strategy and brand hierarchy mean that likefor-like data are expensive and time-consuming to obtain. Moreover, any internal restructuring can make the data model obsolete overnight. Local man- 
agers are also negatively impacted by the lack of global information. Sawhney (Sawhney 2001) discusses the example of Procter \& Gamble where local brand managers were forced to create their own advertising campaign from scratch because they couldn't gain access to previous similar campaigns undertaken elsewhere around the world. In 1994, P\&G solved the problem with a central, global ad-serving system that enabled managers to input the product category, market conditions, competitive context and audience demographic and find the closest advertisement to their needs.

Increasingly, global marketing directors need access to information such as:

- What are our master brands globally, how are they performing and which sub-brands should receive investment?

* How profitable are each of our major brands by channel?

* What impact would various options for brand portfolio restructuring have on the bottom line?

\section{Customers}

The examples of customer-related problems arising because of lack of integrated information visibility are endless, ranging from difficulties in being able to assess the profitability of a customer served across multiple business units, through having different parts of the company sometimes competing for the same customers without even knowing it, to challenges in terms of gaining the right customer information in order to design and target new offerings. Many global companies require their suppliers to treat them as a global customer which means the supplier must organize its resources so that the customer receives a similar offering, price and experience no matter where in the world it contacts the supplier. The advent of e-commerce has only served to accelerate this requirement. Moreover, it has exacerbated the problem, as there is no time to 'fix' a global proposition when trading on the Web.

Thomson Financial in the US provides an example of this problem in action. Before they synchronized their customer-related information across the business, sales people had to sort through information from 37 different systems and 23 different data sets (Sawhney, 2001). This made customer response extremely slow and their ability to identify opportunities for product bundling to cross-sell limited. Sawhney also quotes the example of $3 \mathrm{M}$ in the US where each business unit had maintained its own customer database resulting in 40 per cent of the customer records in $3 \mathrm{M}^{\prime} \mathrm{s}$ various US databases having invalid addresses.

Boards today want and need to know metrics about many aspects of their customer relationships, for example:

* How their global customer accounts are performing and where the opportunities are.

* Potential shortfalls on customer service if business units were consolidated or sold off.

* Revenues and profitability of each channel-to-market on a global basis.

As these examples indicate, data integration across an organization arises as a key technology promising to bring to decision-makers clear visibility and complete information necessary for better decision-making. Research shows that systems which integrate data from diverse sources can improve organizational decision-making, since typically most of the information necessary to improve decision-making within a function unit comes from outside the unit (Wetherbe, 1991). Difficulties in linking data across functions also lie behind some of the intractable technical problems of Executive Information Systems (EIS), and when these difficulties are solved the usefulness of EIS, for example, for decision-making by senior executives, is significantly increased (Crockett, 1992).

\section{The Adaptive Enterprise}

Information is a corporate asset as important as any other. The ability to find and analyse the quality global management information, in a context of rapid business change, quickly and cost effectively, will be one of the critical competencies of successful corporations in the 21st century. Organizations increasingly see the preparation and management of information as a core part, not a by-product, of doing business. The avoidance of Garbage In, Garbage Out (GIGO) is a critical success factor in business intelligence projects, particularly when preparing for the 'next phase' of business intelligence where analytic software draws from multiple data silos.

The success of any business today depends on its information awareness and its ability to adapt to rapid change internally and externally. The work of Mendelson and Ziegler, (1999) and Mendelson (2000) demonstrates that the profitability of an organization depends highly on its organizational IQ, which, in turn, is driven by its information awareness and internal knowledge dissemination. Staff need to understand the information that is important to the organization as a whole and be prepared to gather the appropriate information. The organization, in turn, needs to be structured, and have the infrastructure, to share that information effectively and efficiently. The appropriate information technology is critical - giving executives the ability to have a global up-to-date, change-ready view of the organization from any perspective whilst not being con- 
strained by any monolithic, inflexible information systems. The alignment of adaptive well-informed decision-making and strategy with flexible and integrated information systems are key ingredients for creating the adaptive enterprise.

\section{Visibility and Flexibility}

Global boards of enterprises need to maximize two key elements of their management information systems - Visibility and Flexibility. They need the visibility to drill down and across the organization, at global, regional and local levels, to view high quality information they require at a global level. They want to be able to pull apart and manipulate the data which would otherwise be 'hard-wired' in business unit reports with a limited set of pre-set 'views' of the business. For example, they may wish to understand sales of a particular product in their retail chains and pull all this information together to understand the global profitability of their relationship with that supplier.

They also need to be flexible as an organization in order to capitalize on opportunities and react to positive or negative changes. They need flexibility in terms of IT policy across the organization: different units typically have different information processes and needs. When a business runs itself on a matrix basis and is undertaking significant merger and acquisition activity then this flexibility becomes of paramount importance as management needs to be able to view multiple new business structures and models before it implements them. Once implemented, they also need to demonstrate to investors that the decision was justified so they need the ability to show the 'before' and 'after' performance of the new business.

The requirement to achieve both visibility and flexibility often pulls the organization in different directions and many organizations achieve excellence in one only at the expense of the other.

Figure 1 describes four generic types of organization and their current information technology infrastructure. Visibility on the vertical axis shows the number of views of management information an organization can have ranging from a single perspective to multiple - global/regional, customer, product. Flexibility on the horizontal axis ranges from static, where there is little ability to react to business change, to dynamic, where change is a constant factor and the ability to react is high.

The bottom left quadrant (shown in Figure 2) typically contains businesses that experience little change in their environment and therefore require little agility. They are different from businesses in the other three quadrants in that they see no requirement for a structure or supporting systems that change over time. They also tend to have proprietary information systems, or, if not, systems that are not large monolithic or integrated ones. Privately owned businesses with monopolies and public sector organizations are typical examples of these. These are 'Steady State' businesses. For these businesses, they need only one view of the business and they have little requirement to be flexible as their markets and competitors rarely change, if they exist at all. Generally, they have very little need to change.

The businesses in the top-left and bottom-right quadrants of Figure 1 generally want to change in order to manage their businesses better, usually with an objective of achieving the visibility and flexibility of the adaptive enterprise.

The bottom right quadrant - the decentralized enterprise (shown in Figure 3) - is one for whom time and speed in all business operations is of the essence. This category features businesses which have a great deal of flexibility in terms of their ability to view and manipulate information at a business unit or local level but which have very limited visibility of the business from a 'global' perspective, whether that means geography, global customers or suppliers or product/brand portfolio. These businesses can react to changes in the marketplace quickly, but not always in an informed way, through changes and additions of local units. Generally, these businesses have installed best-of-breed software for each application - ERP, CRM, SCM - and typically have a few systems in different geographic locations or units. This best-of-breed strategy may have been chosen, but more probably it has been thrust upon them as a consequence of acquiring companies with disparate IT systems. In all probability, they would like to move to the standardized enterprise model in the top-left quadrant in Figure 1 in order to achieve greater visibility of their business performance. However, in most cases, the cost and time required to design and install the system, to make all business units conform, and risk sub-optimal performance whilst the change occurs, makes such a move prohibitively expensive.

The top left quadrant - the standardized enterprise (shown in Figure 4) - encompasses businesses that have a very good view of their business from all perspectives, i.e. geographic, customer or product, but which have very little flexibility either because they don't need it or can't achieve it. These organizations generally have a very strong central IT function, which is backed by the board to create one unified structure for IT. They typically will have invested in enterprise software from one vendor, such as ERP and data warehouse, and will have implemented it globally. Businesses typically found in this space include those that have grown organically and those that have such a defined offering worldwide that strict process conformity throughout the value chain 


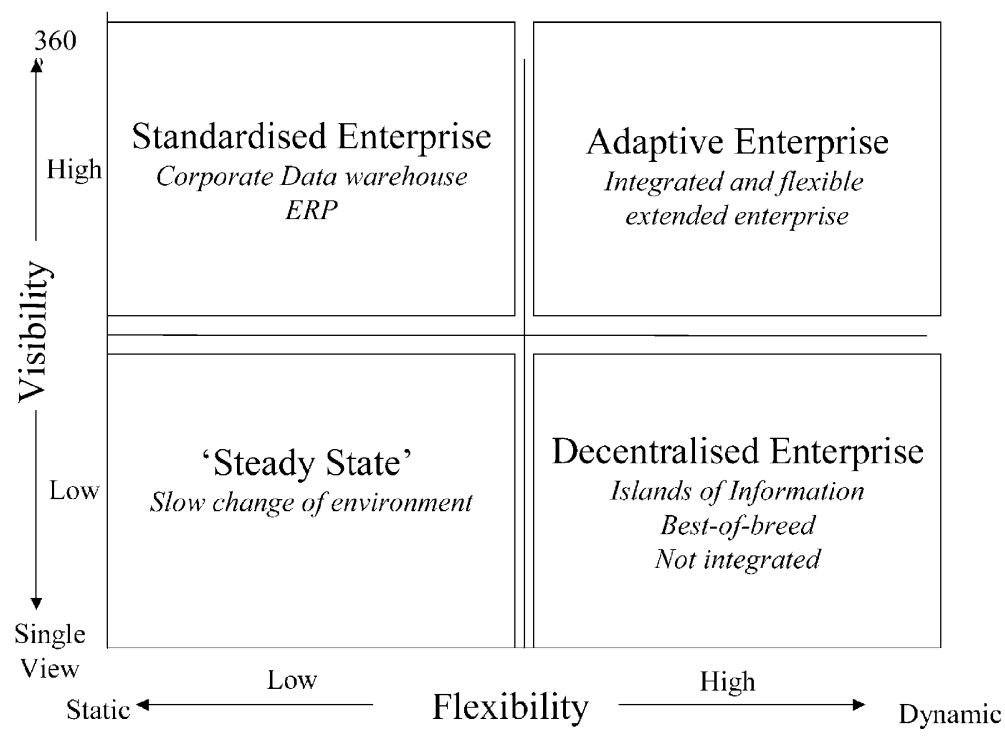

Figure 1 Visibility and Flexibility

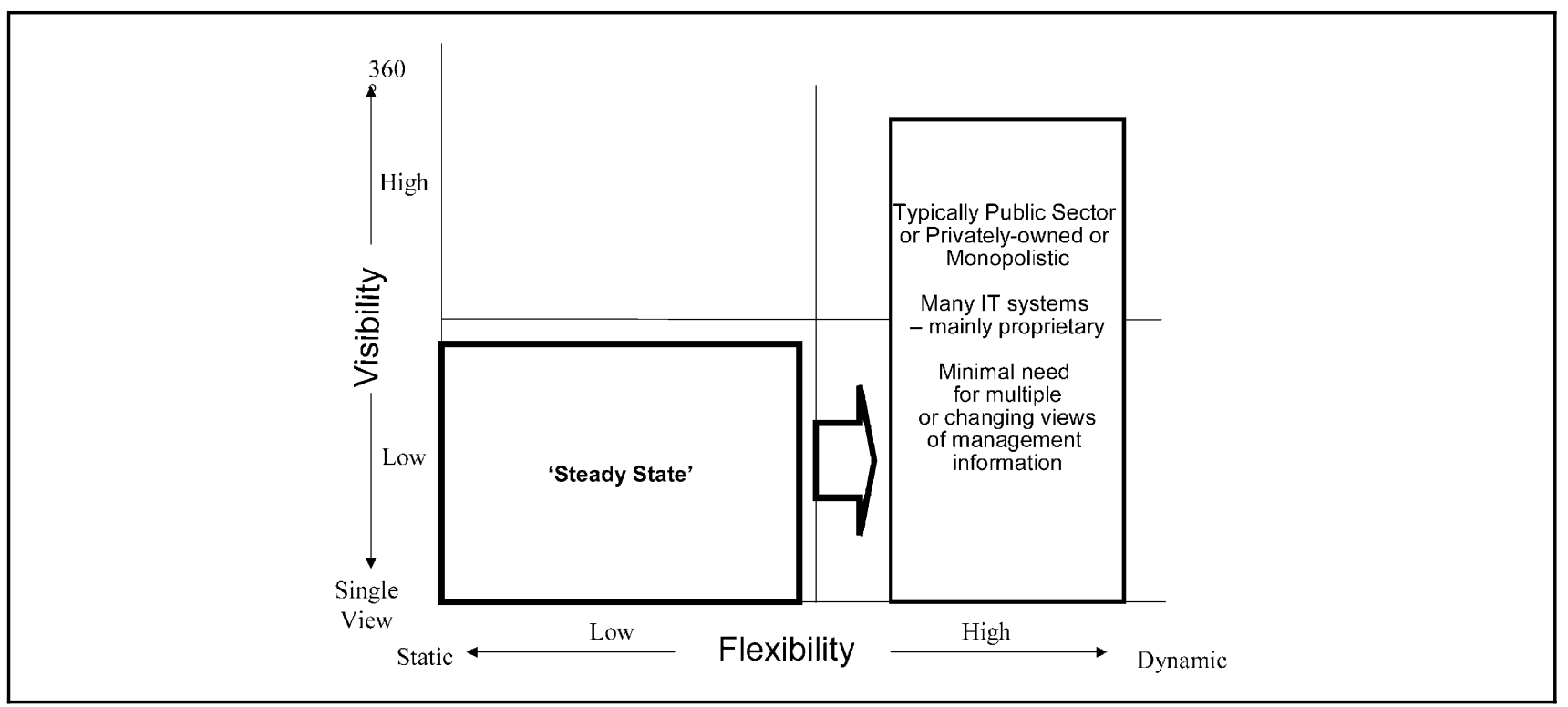

Figure 2 A Steady State Environment and Enterprise

is critical to business success. The standardized enterprise is a very strong model for a global consumer-facing business where the service element is a strong part of the brand. Performance of all business units at all levels can be compared easily and quickly. As long as the internal structure of the business or external environment does not change markedly, then the system can provide solid performance management information to the board. However, such stability is far from being realistic, and the disadvantage with this approach is that these enterprises cannot change, acquire or merge businesses without time-consuming software rewrites.

The adaptive enterprise (shown in Figure 5) is to be found in the top right hand corner of Figure 1. These attain the benefits of the standardized enterprise in terms of visibility and the decentralized enterprise in terms of flexibility. These businesses are able to access fast, available information on any aspect of the business at any level from any perspective no matter how often it changes, and at the same time be flexible and keep this visibility across the entire organization through major changes of the internal and external environment. This approach enables both the business to become highly federated, devolving flexibility and responsibility to those at the business 'coalface', and enables the management to retain overall insight into the way the business and market is developing on a real-time basis at all levels. In this way the business remains both agile and informed both at a global and local level.

The adaptive enterprise concept — in terms of man- 


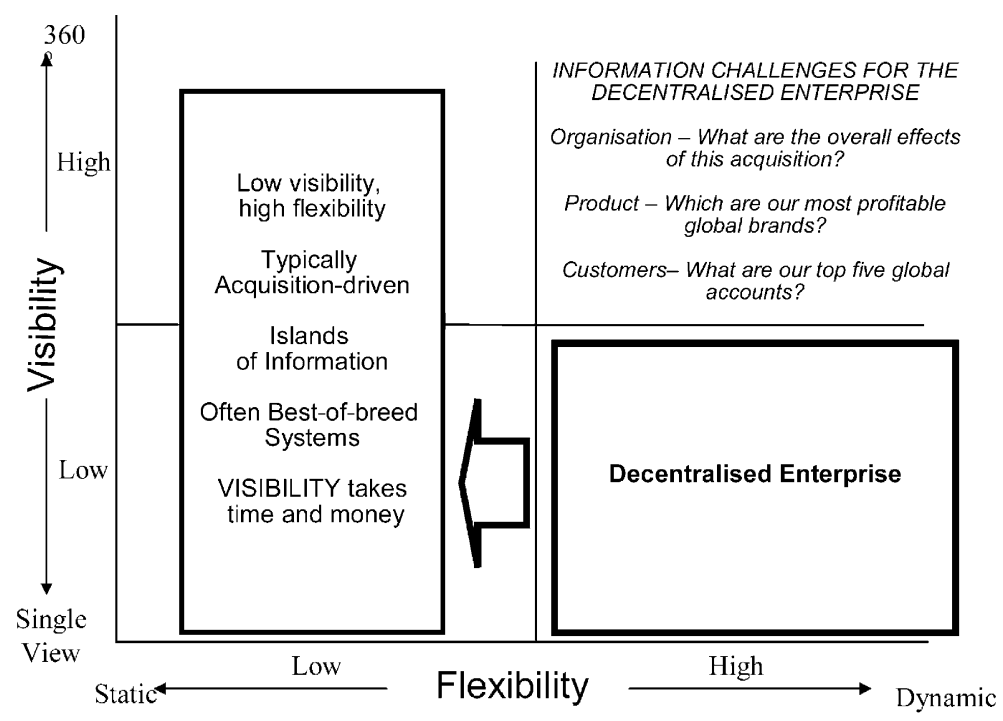

Figure 3 A Decentralized Enterprise

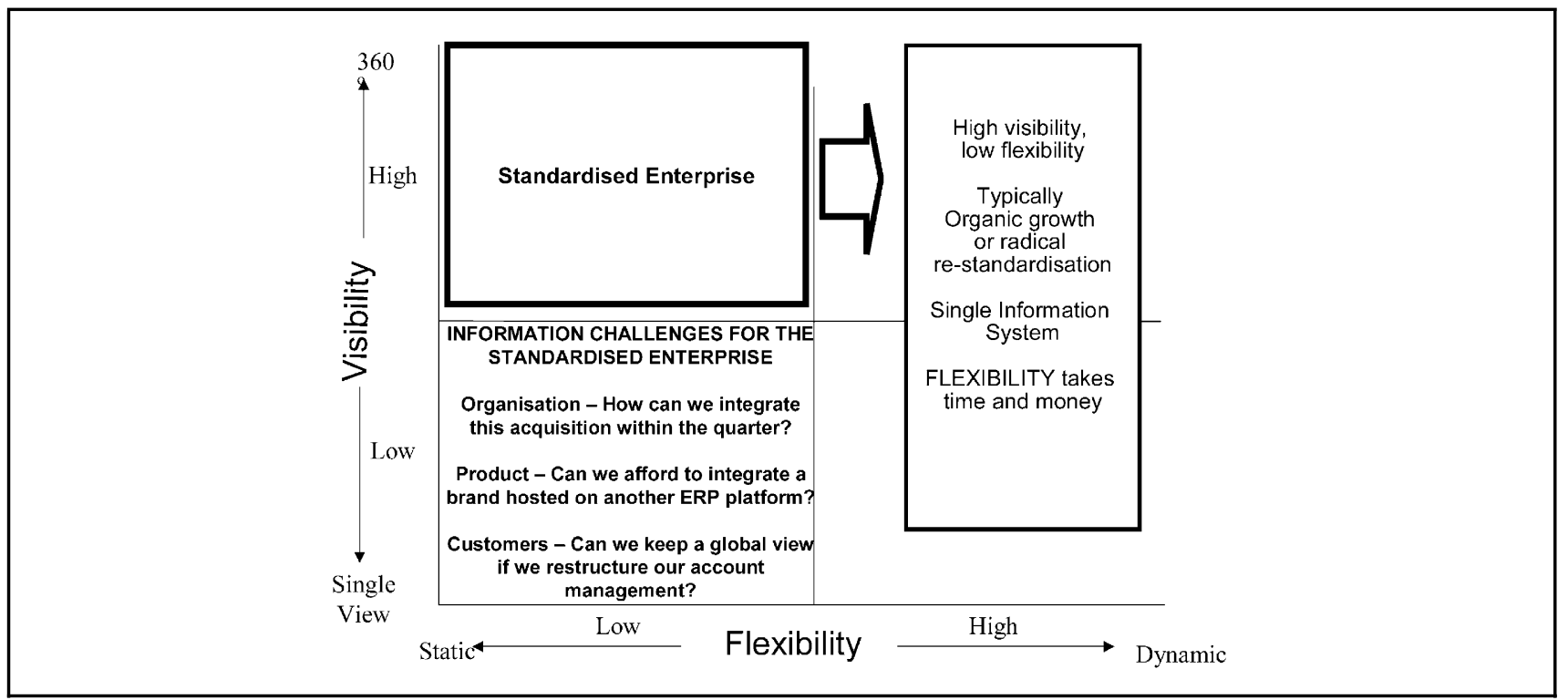

Figure 4 The Standardized Enterprise

agement information strategy, processes and technology - is the state to which both standardized and decentralized enterprises should aspire. The conformity required to analyse information at a global level is achieved without the need to change the way local operations work. The enterprise has the capability to accommodate radical change so that business reports on key performance indicators are still relevant even if there are internal or external changes. As a consequence, boards of matrixed organizations can view their key information on businesses, products, brands, customers and suppliers from any viewpoint or perspective.

In today's volatile environment, with high speed changes and opportunities appearing and disappearing quickly, adapting to new customer needs and exploiting new markets requires high infor- mation awareness and, at the same time, high flexibility. The adaptive enterprise, for example, can create in real-time targeted bundles of products depending on very current, potentially very ephemeral, demand. For example, on 14 January 1999, the day after Michael Jordan's retirement, eBay created a brand new storefront devoted totally to Jordan's memorabilia - in effect creating a new version of itself (Sawhney, 2001).

For larger, more complex, global corporations the creation of the adaptive enterprise is a greater challenge. Here the adaptive enterprise also needs to have the capability to view possible scenarios at a global and regional level without hindering the dayto-day activities of the geographic, product and customer business units. It can view company, product and customer information in 'as was', 'as is' and 'as 


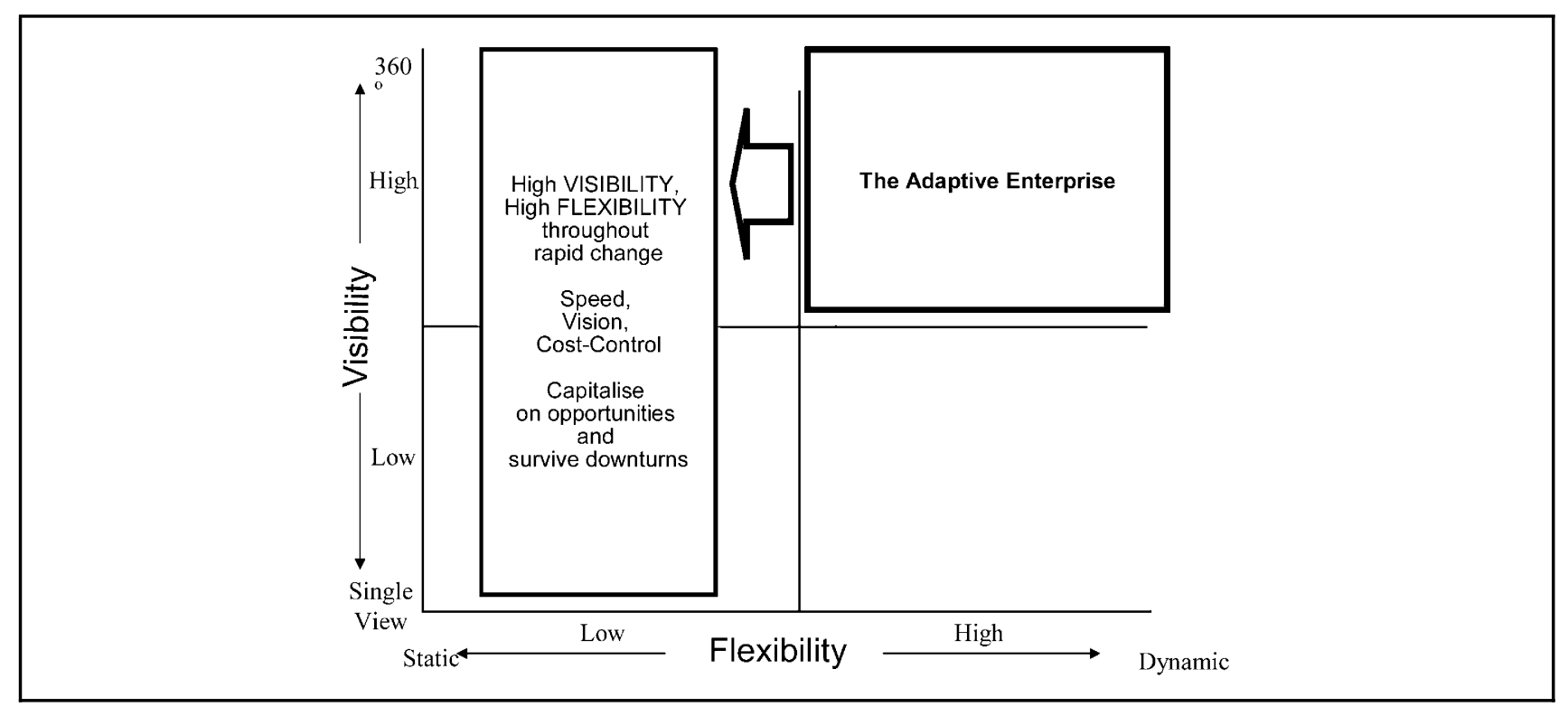

Figure 5 The Adaptive Enterprise

\begin{tabular}{|c|}
\hline $\begin{array}{c}\text { Business-to-Business Integration } \\
\text { EDI,UML,Supply Chain Integration, On-line Trading Brokers }\end{array}$ \\
\hline $\begin{array}{c}\text { Process Integration } \\
\text { Process or Workflow Modeling }\end{array}$ \\
\hline $\begin{array}{c}\text { Application Integration } \\
\text { Application Adapters }\end{array}$ \\
\hline $\begin{array}{c}\text { Component Integration } \\
\text { Transaction Management, Common Application Services, Business Logic }\end{array}$ \\
\hline $\begin{array}{c}\text { Data Integration } \\
\text { Tools for Extracting, Transforming and Loading Data, Metadata } \\
\text { Management }\end{array}$ \\
\hline $\begin{array}{c}\text { Platform Integration } \\
\text { Messaging, ORBs, RPCs, Publish and Subscribe }\end{array}$ \\
\hline
\end{tabular}

Figure 6 EAI Market Segmentation

if' scenarios so that the past and potential success of strategic decisions can be accessed and new strategic options analysed.

\section{Where to Start and Direct for the Future}

If an organization wishes to answer some of the questions above and become an adaptive enterprise then top-level management commitment is a prerequisite. For example it is estimated that one-half to twothirds of all initial data warehouse efforts fail (Kelly, 1997), the most common reasons for failure include weak sponsorship and management support, inadequate user involvement, and organizational politics (Watson et al., 1999). The work of Wixom and Watson (2001) also stresses that for the success of a data warehousing project, the $\mathrm{CEO}$ and his team need to invest their time and funds over a sustained period.
In my view, this is even more true for the creation of an adaptive enterprise.

Like all investment decisions, fast and positive return-on-investment (ROI) is critical. For this reason most companies wishing to evolve into an adaptive enterprise, start with a strategic project with which to apply the adaptive enterprise principles. This could be in the form of core financial reporting issues or externally located requirements such as global customer account management or supply chain management. Typically, the project revolves around an event or a pressing strategic need.

If an organization starts pragmatically addressing a strategic project then it has the opportunity to investigate the potential of this approach whilst minimizing the risk. If the project is successful, the business principles and processes can then be applied to other projects in the enterprise. Once a series of projects have 
been completed successfully, then the organization will be in a position to apply the processes, and accompanying technologies, to the overall organization, in short, to become an adaptive enterprise.

Information integration for global visibility, while keeping local flexibility, is a big challenge. It is only now that robust information technology has become available which can manage both change and complexity. It is well documented by research (Goodhue et al., 1992a) that the net benefits of 'forced' (i.e. all departments agree to share a particular data representation and organization) data integration are not always positive. Research has shown that they depend on three main organizational factors: (a) the interdependence of the business (sub)units, (b) the need for locally unique or flexible action by (sub)units, and (c) the difficulty of designing and implementing systems with integrated data (Goodhue et al., 1992a). With the rise of integration technology that provides fast and easy 'automatic' data integration, these problems can all be avoided and the path to becoming an adaptive enterprise can be fully supported by information technology. Integration technology, within the space of EAI as described in Figure 6 (Gold-Bernstein, 1999), promises to free enterprises from the inflexibility that monolithic enterprise information systems create, while at the same time keep the visibility levels of the organizations high. It is now up to further research and its implementation to see if this promise will be kept and drive IT strategies that lead to the creation of the adaptive enterprise as outlined above.

\section{References}

Crockett, F. (1992) Revitalizing executive information systems. Sloan Management Review 33(4), 39-47.

Davenport, T. (1998) Putting the enterprise into the enterprise system. Harvard Business Review Jul-Aug, 121-131.

Gold-Bernstein, B. (1999) EAI market segmentation. EAI Journal, www.eaijournal.com, Jul-Aug.

Goodhue, D., Wybo, M. and Kirsch, L. (1992a) The impact of data integration on the costs and benefits of information systems. MIS Quarterly September, 293-310

Kelly, S. (1997) Data Warehousing in Action. John Wiley \& Sons, Chichester.

Mendelson, H. (2000) Organizational architecture and success in the information technology industry. Management Science 46(4)

Mendelson, H. and Ziegler, J. (1999) Survival of the Smartest: Managing Information for Rapid Action and World-class Performance. John Wiley \& Sons, Chichester.

Sawhney, M. (2001) Don't homogenize, synchronize. Harvard Business Review 79(7).

Watson, H., Gerard, J., Gonzalez, L., Haywood, L. and Fenton, D. (1999) Data warehousing failures: case studies and findings. Journal of Data Warehousing 4(1), 44-55.

Wetherbe, J. (1991) Executive information requirements: getting it right. MIS Quarterly 15(1), 51-66.

Wixom, B. and Watson, H. (2001) An empirical investigation of the factors affecting data warehousing success. MIS Quarterly 25(1), 17-41.

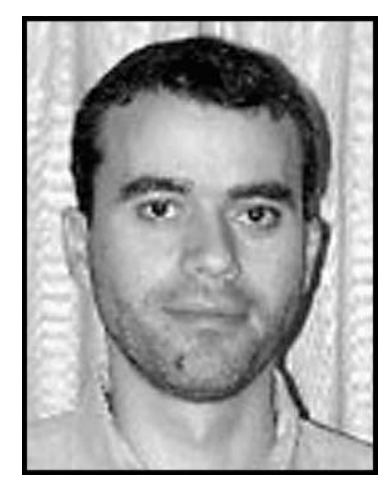

THEODOROS

EVGENIOU, INSEAD,

Technology Management, boulevard de Constance, Fontainebleau, 77305, France. E-mail:theodoros.evgeniou@insead.edu

Dr. Theodoros Evgeniou is Assistant Professor of Information Systems at INSEAD and affiliated with the Center for Biological and Computational Learning at MIT. Current research is into data mining and business intelligence, developing technologies in these fields as well as studying their strategic impact on digital business. 